Periódico do Núcleo de Estudos e Pesquisas sobre Gênero e Direito Centro de Ciências Jurídicas - Universidade Federal da Paraíba

V. 7 - Nº 03 - Ano 2018 - Educação, Gênero \& Direitos Humanos ISSN | 2179-7137 | http://periodicos.ufpb.br/ojs2/index.php/ged/index

\title{
A DESCOBERTA DA HOMOSEXUALIDADE FEMININA NA ADOLESCÊNCIA: NOTAS SOBRE A ACEITAÇÃO E O PRECONCEITO ESCOLAR
}

Resumo: O presente artigo propõe-se a relatar a experiência de acompanhar os desafios em torno da descoberta da homossexualidade por uma adolescente de 16 anos. Esse acompanhamento foi realizado pelo Serviço de Psicologia de uma escola privada de um município no interior do Rio Grande do Sul. Destacase a compreensão acerca do lugar da adolescente e de suas inquietações no contexto escolar, sendo permeado por preconceitos, estigmas e intolerâncias. Ao analisar o caso, percebeu-se sua trajetória, os sofrimentos e as angústias, que foram narrados durante os atendimentos com a psicóloga. Tais atendimentos apontam para a importância da escuta no ambiente escolar, pois essa acolhida ajudou a jovem a conduzir suas descobertas com mais tranquilidade.

\section{Palavras-Chave: $\quad$ Adolescência;}

Homossexualidade; Preconceito; Escola.

\begin{abstract}
This article aims to report on the experience of meeting the challenges of discovering homosexuality by a 16year-old girl. This monitoring was carried out by the Psychology Service of a private school of a municipality in the interior of Rio Grande do Sul. It is important to understand the place of the adolescent and her anxieties in the school context, permeated by prejudices, stigmas and intolerances. In analyzing the case, we noticed her trajectory, the sufferings and the anguish, which were narrated during the consultations with the psychologist. These calls point to the importance of listening in the school environment, as this acceptance helped
\end{abstract}

\footnotetext{
${ }^{1}$ Psicóloga, Mestre em Diversidade Cultural e Inclusão Social (Universidade Feevale).

2 Psicóloga, Mestre e Doutora em Psicologia do Desenvolvimento (UFRGS). Professora do Curso de Psicologia e do Programa de Pós-Graduação em Diversidade Cultural e Inclusão Social (Universidade Feevale).
} 
Periódico do Núcleo de Estudos e Pesquisas sobre Gênero e Direito Centro de Ciências Jurídicas - Universidade Federal da Paraíba V. 7 - No 03 - Ano 2018 - Educação, Gênero \& Direitos Humanos ISSN | 2179-7137 | http://periodicos.ufpb.br/ojs2/index.php/ged/index

the young woman to conduct her discoveries more peacefully.

Keywords: adolescence. homosexuality. Preconception; School.

\section{Introdução}

A sexualidade humana é uma dimensão da experiência social permeada por inúmeras questões. Podese dizer que é um jogo que fabrica intercâmbios de significados entre o "eu" e o "outro", o "eu" e o "nós", o "nós" e “eles”. Enfim, acontece no âmbito destas inter-relações. É na adolescência que a sexualidade se encaminha para uma definição, em termos de orientação, o que provoca inúmeros conflitos, que são, sobretudo, vividos no contexto escolar. Este estudo propõe-se a relatar a experiência de acompanhar os desafios em torno da descoberta da homossexualidade por uma adolescente de 16 anos, que será aqui identificada como Maria. Tal acompanhamento foi realizado pelo Serviço de Psicologia de uma escola privada de um município no interior do Rio Grande do Sul.
Para Vasconcelos (2002), um dos maiores desafios apresentados à escola atual é trabalhar com a reelaboração crítica e reflexiva do educando, a fim de prepará-lo para o mundo atual. Nessa perspectiva, a escola deve transcender o sentido de repasse de conhecimentos, transformando-se num instrumento de crescimento pessoal.

A escola é um lugar privilegiado de vivência da adolescência. Nesse sentido, tem um compromisso de favorecer o encontro de subjetividades, despertando questionamentos, provocando reflexões críticas, levando a vida do aluno para dentro da escola, instigando-o a questionar a sua realidade e contribuindo para que venha a ter consciência do seu papel na construção da sociedade (Grinspun, 1994). Percebese que principalmente no período da adolescência as reflexões com relação à identidade e gênero tornam-se mais premente. A identidade de gênero é o elemento chave no desenvolvimento da personalidade. Influencia o modo de ser, agir e pensar dos indivíduos e constituise no conjunto de crenças, atitudes e estereótipos do indivíduo acerca de gênero, que têm origem em antecedentes 
Periódico do Núcleo de Estudos e Pesquisas sobre Gênero e Direito Centro de Ciências Jurídicas - Universidade Federal da Paraíba V. 7 - No 03 - Ano 2018 - Educação, Gênero \& Direitos Humanos ISSN | 2179-7137 | http://periodicos.ufpb.br/ojs2/index.php/ged/index

biológicos, psicológicos e sociais (Papalia e Olds, 1998).

$\mathrm{Na}$ caminhada desse estudo, de caráter qualitativo, foram realizadas entrevistas livres com a adolescente e constatou-se a importância e a relevância deste tema e os impactos do mesmo nos jovens e na sociedade como um todo. Destaca-se, nesse relato, a compreensão acerca do lugar da adolescente e de suas inquietações no contexto escolar, sendo permeado por preconceitos, estigmas e intolerâncias.

As reflexões deste estudo têm como ponto de partida uma atividade escolar, conduzida por um dos professores, em que os alunos tinham que elaborar uma autobiografia. Nesse escrito, Maria narrou uma experiência de homoafetividade vivida com uma amiga e colega de escola. Posteriormente, essa jovem procurou o Setor de Psicologia de sua escola em busca de escuta para as descobertas em relação à identidade sexual e à aceitação da homossexualidade. Ela foi escutada pela primeira autora desse trabalho.

Os encontros com a jovem ocorreram durante um período do ano de 2011. Nesses encontros, Maria falava das angústias que foram acionadas ao escrever a autobiografia, que será objeto de análise no presente trabalho, considerando os aspectos subjetivos e as motivações de ordem consciente ou inconsciente. Nesse sentido, buscou-se a interpretação desses dados, considerando o contexto em que eles emergiram (Cardoso, 2010).

\section{O Caso e a Experiência da}

\section{Homosexualidade em Pauta}

O caso a ser relatado é de uma adolescente de 16 anos, estudante do Ensino Médio de uma escola privada de um município do interior do Rio Grande do Sul. Os fragmentos, a seguir, referemse ao trabalho realizado pela aluna no ano de 2011, intitulado de autobiografia.

Minhas memórias começam a ficar mais claras quando perto de meus quatro anos. Lembro-me de meu primeiro dia no Colégio. Quando cheguei a minha sala de aula percebi como tudo aquilo poderia ser divertido. Estava otimista. Não fiz nenhum escândalo. - Tu não vai embora? Vai ficar aqui a tarde inteira? Deu pra ver que ela se surpreendeu, mas parecia aliviada. Sua filha não estava fazendo escândalo para que a mãe não fosse embora. Ótimo! 
Periódico do Núcleo de Estudos e Pesquisas sobre Gênero e Direito Centro de Ciências Jurídicas - Universidade Federal da Paraíba V. 7 - No 03 - Ano 2018 - Educação, Gênero \& Direitos Humanos ISSN | 2179-7137 | http://periodicos.ufpb.br/ojs2/index.php/ged/index

Nesse excerto da autobiografia, Maria refere sua entrada na escola como algo que fora tranquilo. Destaca que ela foi destemida num momento de separação que costuma gerar angústia e conflitos. Destaca a confiança que parecia ter perdido no momento em que buscou escuta no Serviço de Psicologia.

Meu primeiro contato com Ruth [pseudônimo para colega] foi um ano antes, quando o colégio decidiu juntar duas turmas. Sentávamos lado a lado. Eu gostava de usar os lápis de cor dela, que Ruth emprestava com a maior satisfação. Essa sempre foi uma de suas características: a generosidade. Mas logo descobri que gostava também de conversar com ela. Conversávamos bastante, nos ajudávamos nos exercícios. Em 2006 nossa amizade fortaleceu-se muito e a partir daí nos tornamos, e também deixamos de nos tornar, inseparáveis por muitas vezes.

Entende-se que é através do convívio escolar que as relações interpessoais, antes restritas ao contato familiar, ganham força e que, ao ingressar na escola, novos direitos e deveres são construídos e a criança ou o jovem passa a compreender sua nova posição social. Sendo mais valorizado, adquire novos conhecimentos $\mathrm{e}$ estabelece novas relações sociais (Hamdan, 1998), assim como referido no comentário de Maria quando conhece Ruth e percebe a importância dela em sua vida.

Conforme outro recorte da autobiografia: "Já estávamos em 2008 e eu tinha 12 anos. Passei a adotar um visual da moda. Franja para o lado, caindo no olho. Ver-me de preto ou usando roupas de listrinhas não era nada raro. É, eu já fui EMO um dia”. Nesse momento, Maria ressalta a busca de uma diferenciação com relação ao corpo infantil, uma procura pelo que pode combinar com o jeito de ser, construindo, assim, a sua identidade. Maria começa a fazer as suas buscas. Becker (1997) faz uma referência à metáfora da lagarta, que, ao iniciar a construção do seu casulo, dá um passo em direção a sua metamorfose. Este ser que vivia em contato íntimo com a natureza e a vida exterior, se fecha dentro de si mesmo, para dar início à transformação que levará a outro ser, dotado de asas, que lhe permitirão voar. Conforme Becker, se a lagarta pensa e sente, também o seu pensamento e o seu sentimento se transformarão. Serão agora o pensar e o sentir de uma borboleta. Maria, em sua narrativa, na autobiografia, destaca as 
Periódico do Núcleo de Estudos e Pesquisas sobre Gênero e Direito Centro de Ciências Jurídicas - Universidade Federal da Paraíba V. 7 - No 03 - Ano 2018 - Educação, Gênero \& Direitos Humanos ISSN | 2179-7137 | http://periodicos.ufpb.br/ojs2/index.php/ged/index

suas descobertas, suas transformações e os novos laços de amizade que foram se constituindo:

O mais incrível foi como tudo começou e terminou. Repentino, com a rapidez de um vendaval. Todos esqueceram e ninguém mais se importa. Porém nunca irei esquecer. Já em junho de 2008 ninguém mais se lembrava de nada e comecei a fazer novas amizades. Não era apenas eu que havia crescido.

Quando Joana (uma terceira amiga que instigou o ciúme e a reflexão sobre a amizade) surgiu na vida de Maria, como colega de aula, transferida de turno, esta ressaltou que a presença da nova colega a incomodava, sobretudo por causa do seu jeito mais ousado e insistente (sempre chegando muito perto e às vezes sendo invasiva demais). Neste momento, as questões sobre identidade sexual começaram a mexer com Maria. Tal incômodo referia-se às próprias dúvidas dela. Afinal, como lidar com o outro, por quem sinto atração e repulsa, desejo e medo?

Atualmente, ao longo da adolescência, é comum observarmos iniciações e experiências de caráter homossexual, na medida em que as meninas convivem com suas amigas intimamente, trocando confidências, $\mathrm{o}$ que, muitas vezes, as levam para um contato corporal, tais como beijos, toques e outras experiências sexuais. A adolescência, por si só, é uma fase de experimentações, que são fundamentais para a construção da identidade sexual. A identidade sexual refere-se a uma construção que ocorre ao longo da vida do indivíduo, baseada em um conjunto de experiências, práticas cotidianas relacionadas ao prazer, à intimidade e às expressões amorosas, e conserva características que o possibilita pertencer a determinado grupo cultural (Pinho e Pulcino, 2016).

“A sexualidade não é apenas uma questão pessoal, mas é social e política. Ela é aprendida, ou melhor, é construída, ao longo de toda a vida, de muitos modos, por todos os sujeitos" (Menegon e Silva, 2015: 123). A identidade sexual se define e se afirma durante todo o processo evolutivo, pela identificação, assim como é no âmbito da cultura e da história, conforme menciona Menegon e Silva (2015), que se definem as identidades sociais (todas elas e não apenas as identidades sexuais e de gênero, mas também as identidades de raça, de nacionalidade, de classe etc.). 
Periódico do Núcleo de Estudos e Pesquisas sobre Gênero e Direito Centro de Ciências Jurídicas - Universidade Federal da Paraíba V. 7 - No 03 - Ano 2018 - Educação, Gênero \& Direitos Humanos ISSN | 2179-7137 | http://periodicos.ufpb.br/ojs2/index.php/ged/index

Louro (1997: 21) também destaca as questões culturais na construção da identidade sexual. Para ele, é

necessário demonstrar que não são propriamente as características sexuais, mas é a forma como essas características são representadas ou valorizadas, aquilo que se diz ou se pensa sobre elas, que vai constituir, efetivamente, o que é feminino ou masculino em uma dada sociedade e em um dado momento histórico.

Podemos pensar também na questão de gênero, ou a identidade de gênero, como pontua Quaresma da Silva (2008: 5),

o corpo, visto por essa perspectiva, é um construto social a cultural alvo de diferentes e múltiplos marcadores identitários. O que se percebe, dessa forma, é que as representações são inventadas, produzidas e que, por sua repetição, tornam-se hegemônicas e hierarquizam os sujeitos na escala social de acordo com diversos atravessamentos, tais como as questões de gênero.

Estes atravessamentos perpassam o ambiente escolar e o convívio delas com suas amigas e colegas. "As representações circulam na esfera do social e legitimam o direito de capturar, nomear, enfim, de representar os sujeitos, pois somos prisioneiros das representações e do nosso próprio tempo já vivido e ainda por viver" (Quaresma da Silva, 2008: 5).

A relação com Joana sempre remetia à fronteira entre amizade ou algo mais, porém sempre com o caráter de descobertas e jogos sexuais próprios do adolescente. $\mathrm{O}$ surgimento de uma terceira pessoa, no caso a Joana, fez com que fossem gerados ciúmes e conflitos entre as duas, pois não era mais a dupla e sim o trio, ou melhor, a Ruth e a Joana disputando espaço com a Maria.

Várias vezes ambas, Maria e Joana compareceram ao Serviço de Psicologia para conversar sobre estes sentimentos. Durante um destes momentos, Maria manifestou a dúvida se era amizade ou amor que sentia pelas amigas. Joana se declarou dizendo que estava apaixonada por ela e esta, então, começou a se questionar se o que vivenciou com a Ruth foi amizade ou amor.

Nas entrevistas, Joana comentava que tentou várias vezes se aproximar de forma mais íntima de Maria e esta sempre fugia. Quando Joana resolveu desistir e dizer que iria deixá-la em paz e se afastar, Maria começou a sentir falta 
Periódico do Núcleo de Estudos e Pesquisas sobre Gênero e Direito Centro de Ciências Jurídicas - Universidade Federal da Paraíba

V. 7 - No 03 - Ano 2018 - Educação, Gênero \& Direitos Humanos ISSN | 2179-7137 | http://periodicos.ufpb.br/ojs2/index.php/ged/index

dela e então percebeu que havia algo mais.

Além das transformações físicas, a adolescência é marcada pelas descobertas e pela busca da superação de obstáculos. As novas experiências na adolescência podem desencadear sentimentos de medo e insegurança. Como o sexo é algo desconhecido no universo do adolescente, este tende a iniciar cada vez mais precocemente a prática de relações sexuais, muitas vezes até mesmo por pressão do grupo social no qual se encontra engajado (Fenwicke, 1996).

Este medo estava sempre presente nos sentimentos de Maria, relatados nas entrevistas, até ela conseguir perceber o que realmente sentia por Joana. Assim como outras considerações, cabe ressaltar sobre os sentimentos de Maria. Durante esta angústia, permeada de dúvidas e incertezas, Maria sofria com a baixa autoestima, julgando-se feia e que ninguém gostava dela, pois gostava de um menino que não gostava dela. Isto desencadeou sintomas bulímicos e de automutilações. Então, além dos conflitos compatíveis com a fase da adolescência, Maria também vivia um conflito de se ver inferior aos que compunham o seu grupo. Esse conflito a levava a sintomas que a colocavam em risco.

Ruth também percebeu que estava apaixonada por Maria. Joana não suportou e pediu transferência da escola, sempre com o monitoramento e acompanhamento do Setor de Psicologia. Através de conversas com a mãe de Joana (mais compreensiva diante de todo conflito) foi possível encaminhar a troca de escola, pois Joana sentia-se mal compreendida por Maria e isto estava afetando a relação dela com o grupo também.

Maria encontrava-se na etapa de estranhamento, transitando entre uma grande amizade e a experiência homossexual, permeada por preconceitos. Diante destes conflitos, houve uma discrepância familiar. Joana contou tudo a sua mãe e esta lhe apoiou, como o auxílio e acompanhamento do Serviço de Psicologia. Já a mãe de Maria negava e nem imaginava que isto poderia ter acontecido. Ela, em todos os contatos com a escola, mostrava-se como uma mãe inflexível e com muitos 
Periódico do Núcleo de Estudos e Pesquisas sobre Gênero e Direito Centro de Ciências Jurídicas - Universidade Federal da Paraíba V. 7 - Nº 03 - Ano 2018 - Educação, Gênero \& Direitos Humanos ISSN | 2179-7137 | http://periodicos.ufpb.br/ojs2/index.php/ged/index

preconceitos, com relação às questões da sexualidade.

Foucault (1979), nesse sentido, traz uma importante reflexão sobre as relações de poder e a heteronormatividade,

(...) em uma sociedade como a nossa, que tipo de poder é capaz de produzir discursos de verdade dotados de efeitos tão poderosos? [...] estamos submetidos à verdade também no sentido em que ela é lei e produz o discurso verdadeiro que decide, transmite e reproduz, ao menos em parte, efeitos de poder. Afinal, somos julgados, condenados, classificados, obrigados a desempenhar tarefas e destinados a um certo modo de viver ou morrer em função dos discursos verdadeiros que trazem consigo efeitos específicos de poder (Foucault, 1979: 179-180).

Diante disso, cabe pontuar o preconceito, como uma característica psicológica do indivíduo. Nunan (2017) refere que os indivíduos estigmatizados estão frequentemente expostos a ameaças diretas e indiretas a sua autoestima. Nunan (2017: 248) também ressalta as repercussões do preconceito:

Os eventos de vida negativos decorrentes do preconceito institucionalizado e da discriminação podem ser chamados de estressores externos, enquanto que os estressores internos seriam aqueles ligados ao preconceito internalizado. Em outras palavras, pode-se dizer que quando o estereótipo é muito forte ou pernicioso, membros do grupo alvo tendem a aceitá-lo e incorporá-lo à sua autoimagem, fazendo com que sentimentos negativos com relação à própria orientação sexual sejam generalizados para o self como um todo.

Costa, Bandeira e Nardi (2015) reconhecem que é impossível discutir o preconceito com relação a orientações não heterossexuais no Brasil sem levar em consideração o preconceito direcionado às expressões de gênero que se desviam das já estabelecidas. Ou seja, se um homem, seja homossexual ou heterossexual, no contexto brasileiro, manifesta comportamentos culturalmente considerados femininos, será alvo de preconceito. Desta forma, podemos questionar a função dos papeis de gênero na vida destes indivíduos, como se constituem as masculinidades e as feminilidades e como isso afeta no processo de formação de identidade.

Todas as pessoas têm preconceitos, ou seja, preconcepções que inserem em seus cotidianos quase sempre sem saber exatamente do que se trata e de onde vêm aquelas ideias. Em relação à homossexualidade não seria diferente, pois foge da lógica 
Periódico do Núcleo de Estudos e Pesquisas sobre Gênero e Direito Centro de Ciências Jurídicas - Universidade Federal da Paraíba V. 7 - No 03 - Ano 2018 - Educação, Gênero \& Direitos Humanos ISSN | 2179-7137 | http://periodicos.ufpb.br/ojs2/index.php/ged/index

heteronormativa. Nessa perspectiva, Silva (2017: 104) destaca que:

Há de se convir que o preconceito e a discriminação direcionadas aos homossexuais não derivam exclusivamente da ignorância. Eles estão fundados, principalmente, na promoção da ordem heterossexual, que faz apologia à heterossexualidade como a única forma possível de expressão sexual, em detrimento de inúmeras outras formas de expressão da sexualidade.

Britzman (1996: 83) afirma que “a rearticulação do significante 'homossexualidade' exige que a heterossexualidade seja desvinculada dos discursos da naturalidade e dos discursos da moralidade. A heterossexualidade deve ser vista como uma possibilidade entre muitas". Ainda Britzman (1996: 74) traz outra reflexão sobre esta questão,

nenhuma identidade sexual -
mesmo a mais normativa - é
automática, autêntica, facilmente
assumida; nenhuma identidade
sexual existe sem negociação ou
construção. Não existe, de um
lado, uma identidade
heterossexual lá fora, pronta,
acabada, esperando para ser
assumida e, de outro, uma
identidade homossexual instável,
que deve se virar sozinha.

Essa luta era constantemente vivida por Maria para fugir do conflito, pois estava fora dos padrões ditados pela mãe e pela sociedade. Estes padrões tornam a relação com o outro mais confortável, mas para quem luta por uma legitimidade, por um reconhecimento, é uma situação extremamente difícil, ou seja, algo que vai, paulatinamente, ferindo sentimentos, princípios, caráter. Confrontada por essas experiências, Maria precisou de uma escuta atenta e sensível para conseguir elaborar o sofrimento diante desta descoberta.

Nessa perspectiva, a escola também tem um papel importante no momento destas descobertas. Egypto (2003: 1) pontua que:

é fundamental que a escola possa ajudar na formação da identidade e possibilitar um desenvolvimento mais harmonioso, porque todo mundo sabe que a sexualidade é fator essencial na questão da identidade: o "ser menino" ou o "ser menina", o que é ser homem ou mulher, os comportamentos e ações de cada gênero.

Essas são as primeiras questões que aparecem para as crianças na escola e estão relacionadas com a formação de sua identidade. Sendo assim, é importante que a escola trabalhe com um conceito amplo de relações de gênero, que mostre que há infinitas formas de ser 
Periódico do Núcleo de Estudos e Pesquisas sobre Gênero e Direito Centro de Ciências Jurídicas - Universidade Federal da Paraíba V. 7 - Nº 03 - Ano 2018 - Educação, Gênero \& Direitos Humanos ISSN | 2179-7137 | http://periodicos.ufpb.br/ojs2/index.php/ged/index

homem e de ser mulher e de expressar isso.

Costa e Silva (2015: 4), pautando a história da sexualidade, mencionam que

as realidades, no entanto, não são fixas ou imutáveis, mas foram condições históricas e culturais, relações de poder e saber que constituíram essa escola, então é a hora de podemos construir, inventar outras linguagens $\mathrm{e}$ realidades, múltiplas práticas e saberes, diferentes relações de poder e posições de sujeitos que ensinam e aprendem.

Cabe lembrar também que os fundamentos destas condições se encontram na Declaração Universal dos Direitos Humanos, elaborada pelas Nações Unidas e assinada em 1948. Ela reconhece e enumera nos seus trinta artigos o que internacionalmente é considerado direito de todos os seres humanos, independentemente de qualquer particularidade cultural, sexual, religiosa, origem ou de qualquer outra natureza. Nas considerações feitas no preâmbulo da Declaração, faz-se a afirmação e reconhecimento dos direitos universais e positivos que devem estabelecer o limiar de tolerância no convívio social entre todos os grupos humanos (ONU, 1948).
A partir da Carta Constitucional de 1988, a sociedade brasileira pensou ser capaz de construir relações sociais justas, com base nos direitos que visam à realização da cidadania na luta pela justiça social e superação das desigualdades e preconceitos. Neste contexto, o Ministério Público se destaca como um órgão importante no enfrentamento da violação dos direitos constitucionalmente garantidos, onde um deles é a liberdade sexual.

Considerando a especificidade do campo educacional, Gomes (2017: 24801) aborda o papel da educação, em relação aos direitos:

A educação como espaço de
construção de cidadania e
promoção da igualdade social deve
se fazer instrumento de ação e
reflexão na luta contra o
preconceito, a descriminação e a
violência física e simbólica,
expressas de diferentes maneiras
no ambiente educacional da
educação básica as pós-
graduações. Nesse sentido, a
educação, pensada como processo
de desenvolvimento de sujeitos
sociais, deve possibilitar o
rompimento com o passado de
descriminação e preconceito,
propondo ações concretas e
efetivas para a construção de um
presente social mais justo e
igualitário.

Nesta linha de pensamento, entendemos que a escola deva ser um 
Periódico do Núcleo de Estudos e Pesquisas sobre Gênero e Direito Centro de Ciências Jurídicas - Universidade Federal da Paraíba V. 7 - No 03 - Ano 2018 - Educação, Gênero \& Direitos Humanos ISSN | 2179-7137 | http://periodicos.ufpb.br/ojs2/index.php/ged/index

lugar de escuta das realidades $\mathrm{e}$ descobertas dos jovens, diante de incertezas da vida. Tal escuta deve ser sensível às identidades a partir de suas infinitas definições. Sendo assim, a escola também “deve ser um espaço, não como controladora da vontade do sujeito, mas como instância propiciadora de reflexão sobre o assunto" (Costa e Silva, 2015:08)

\section{Considerações Finais}

O presente relato de experiência apontou para o quanto a busca da identidade sexual e a aceitação da homossexualidade na adolescência é um processo permeado por conflitos, necessitando de espaços de escuta sensível e acompanhamento desse processo. Percebe-se em todo o relato de Maria uma busca e uma luta por algo novo e que lhe causava ânsia e estranhamento. O auxílio e o entendimento do processo, pela escuta e acolhimento da escola, facilitou a reflexão dessa descoberta, que fora acompanhada de preconceitos oriundos, sobretudo da família. Diante disso, entende-se ser relevante a escola criar espaços para a discussão da sexualidade e suas descobertas, fazendo uma mediação com as famílias. Se a perspectiva é buscar um avanço, ainda há muito para investir na concepção de singularizar a sexualidade, de modo que ela seja tratada de forma a respeitar as diferenças na escola. Estudos sobre essa temática são fundamentais, uma vez que essa discussão é prioritária na cultura juvenil.

Sabemos que a desconstrução do preconceito diante da homossexualidade não é uma tarefa simples, visto que não é apenas o ato discriminatório isolado que se pretende combater, mas toda uma estrutura social de crenças, valores e atitudes que reforçam esta cultura de exclusão das minorias sexuais. Não ser uma tarefa fácil, não significa que seja impossível. Por isso, é importante que esse tema seja objeto de estudo e investigação, em especial, no campo escolar, para que essa discussão possa contribuir para avanços nesse cenário.

\section{Bibliografia}

Becker, Daniel (1997), O que é adolescência? São Paulo: Brasiliense. 
Periódico do Núcleo de Estudos e Pesquisas sobre Gênero e Direito Centro de Ciências Jurídicas - Universidade Federal da Paraíba V. 7 - No 03 - Ano 2018 - Educação, Gênero \& Direitos Humanos ISSN | 2179-7137 | http://periodicos.ufpb.br/ojs2/index.php/ged/index gos\%20publica\%C3\%A7\%C3\%A3o/26

Britzman, Deborah (1996), “O que é esta coisa chamada amor? Identidade homossexual, educação e currículo". Revista Educação \& Realidade, 21, 7196.

Cardoso, José Miguel (2010), Pesquisa qualitativa: características, usos e possibilidades. São Paulo: Pastoral Gadget.

Costa, Angelo Brandelli; Bandeira, Denise Ruschel; Nardi, Henrique Caetano (2015), “Avaliação do preconceito contra diversidade sexual e de gênero: construção de um instrumento". Estud. psicol. Campinas, 32(2), 163-172. Disponível: http://www.scielo.br/scielo.php?script=s ci_arttext\&pid=S0103166X2015000200 $\underline{163 \& \operatorname{lng}=\text { en } \& n r m=\text { iso. }}$.

Costa, Zuleica; Silva, Denise (2015), Educação sexual no Brasil: uma revisão bibliográfica do período de 2005 a 2015. In: SEFIC 2017, Canoas, RS. (Anais online). Disponível: file:///C:/Users/Usuario/Documents/arti

\section{7-304-1-PB.pdf}

Egypto, Antônio Carlos (2003), Orientação sexual na escola: um projeto apaixonante. São Paulo: Editora Cortez.

Fenwicke, Smith T. (1996), Adolescência: Guia de sobrevivência para pais e adolescentes. São Paulo: Ática.

Foucault, Michel (1979), Microfísica do Poder. Rio de Janeiro: Grall.

Gomes, Candido Alberto (2017), A diversidade sexual como direito humano. Curitiba: IV Seminário Internacional de Representações Sociais Subjetividade e Educação. ISSN 2176-1396. Disponível: http://educere.bruc.com.br/arquivo/pdf2 017/27732_14287.pdf

Grinspun, Miriam P. S. Zippin. A

prática dos orientadores educacionais.

São Paulo: Cortez, 1994.

Hamdan, Amer Cavalheiro (2000), Introdução à psicologia do desenvolvimento. Cárdenas: Campo. 
Periódico do Núcleo de Estudos e Pesquisas sobre Gênero e Direito Centro de Ciências Jurídicas - Universidade Federal da Paraíba

V. 7 - No 03 - Ano 2018 - Educação, Gênero \& Direitos Humanos ISSN | 2179-7137 | http://periodicos.ufpb.br/ojs2/index.php/ged/index

Louro, Guacira (1998), O corpo educado: pedagogias da sexualidade. Belo Horizonte: Autêntica.

Menegon, Carolina; Silva, Enio Waldir da (2015), A sexualidade feminina e a psicanálise: rompendo as amarras da moral sexual cristã e do sexo como reprodução. Rev. Gênero e Direito, 4(3), 122-139

Nunan, Adriana (2010), Preconceito internalizado e comportamento sexual de risco em homossexuais masculinos. Psicologia Argumento, 28(62), 247-259.

Papalia, Diane E.; Olds, Sally W. O mundo da criança. São Paulo: Markon Brooks, 1998.

Pinho, Raquel; Pulcino, Rachel (2016), Desfazendo os nós heteronormativos da escola: contribuições dos estudos culturais e dos movimentos LGBTTT. Educ. Pesqui., São Paulo, 42(3), 665-681.

Quaresma da Silva, Denise (2008). Discurso e gênero: uma discussão sobre modos de enunciar o feminino. Fazendo
Gênero 8 - Corpo, Violência e Poder. ST 8 - Discurso e Gênero: A figura feminina.

Silva, Odacyr de Moura (2017), Trajetórias de vida e mudança de identidade sexual: quando não se encontra o pote de ouro no final do arcoíris. 2017.120f. Dissertação (Mestrado em Psicologia) UFES. Vitória.

Vasconcelos, Celso S. (2002), Coordenação do trabalho Pedagógico. São Paulo: Libertad. 